\title{
Destruction of vasculogenic mimicry channels by targeting epirubicin plus celecoxib liposomes in treatment of brain glioma
}

This article was published in the following Dove Press journal:

International Journal of Nanomedicine

21 March 2016

Number of times this article has been viewed

Rui-Jun Ju',2,*

Fan Zeng ${ }^{1, *}$

Lei Liu'

Li-Min Mu'

Hong-Jun Xie'

Yao Zhao'

Yan Yan'

Jia-Shuan $\mathrm{Wu}^{\prime}$

Ying-Jie $\mathrm{Hu}^{\prime}$

Wan-Liang Lu'

'Beijing Key Laboratory of Molecular Pharmaceutics and New Drug System, State Key Laboratory of Natural and Biomimetic Drugs, School of Pharmaceutical Sciences, Peking University, ${ }^{2}$ Department of Pharmaceutical Engineering, Beijing Institute of Petrochemical Technology,

Beijing, People's Republic of China

*These authors contributed equally to this work

\begin{abstract}
The efficacy of chemotherapy for brain glioma is restricted by the blood-brain barrier (BBB), and surgery or radiotherapy cannot eliminate the glioma cells because of their unique location. Residual brain glioma cells can form vasculogenic mimicry (VM) channels that can cause a recurrence of brain glioma. In the present study, targeting liposomes incorporating epirubicin and celecoxib were prepared and used for the treatment of brain glioma, along with the destruction of their VM channels. Evaluations were performed on the human brain glioma U87MG cells in vitro and on intracranial brain glioma-bearing nude mice. Targeting epirubicin plus celecoxib liposomes in the circulatory blood system were able to be transported across the $\mathrm{BBB}$, and accumulated in the brain glioma region. Then, the liposomes were internalized by brain glioma cells and killed glioma cells by direct cytotoxic injury and the induction of apoptosis. The induction of apoptosis was related to the activation of caspase-8-and -3-signaling pathways, the activation of the proapoptotic protein Bax, and the suppression of the antiapoptotic protein Mcl-1. The destruction of brain glioma VM channels was related to the downregulation of VM channel-forming indictors, which consisted of MMP-2, MMP-9, FAK, VE-Cad, and VEGF. The results demonstrated that the targeting epirubicin plus celecoxib liposomes were able to effectively destroy the glioma VM channels and exhibited significant efficacy in the treatment of intracranial glioma-bearing nude mice. Therefore, targeting epirubicin plus celecoxib liposomes could be a potential nanostructured formulation to treat gliomas and destroy their VM channels.
\end{abstract}

Keywords: brain glioma, vasculogenic mimicry channels, targeting liposomes, epirubicin, celecoxib

\section{Introduction}

Brain glioma is one of the most lethal types of malignant tumors, and has a poor prognosis. ${ }^{1}$ Treatment of brain glioma usually involves a comprehensive strategy, including surgery, radiotherapy, and chemotherapy. ${ }^{2}$ Because of the unique location and highly infiltrating nature of brain glioma, surgery and radiotherapy cannot eliminate brain glioma cells completely. ${ }^{3}$ Furthermore, the efficacy of chemotherapy is also restricted, due to the hindrance of the blood-brain barrier (BBB) ${ }^{4,5}$ In hypoxia, the residual brain glioma cells can form vasculogenic mimicry (VM) channels by remolding, and the generated VM channels provide nutrients to support the growth or recurrence of brain glioma cells. ${ }^{6-8}$

We have previously developed a functional liposome drug-delivery system, ie, targeting epirubicin plus celecoxib liposomes, to treat invasive breast cancer. ${ }^{9}$

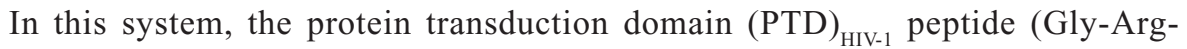
Lys-Lys-Arg-Arg-Gln-Arg-Arg-Arg-Cys-Gly- $\mathrm{NH}_{2}$ ) was modified on liposomes as
Correspondence: Wan-Liang Lu Beijing Key Laboratory of Molecular Pharmaceutics and New Drug System, State Key Laboratory of Natural and Biomimetic Drugs, School of Pharmaceutical Sciences, Peking University, 38 Xueyuan Road, Beijing I00I9I, People's Republic of China $\mathrm{Tel} / \mathrm{fax}+86 \quad 1082802683$

Email luwl@bjmu.edu.cn
Dovepress

http://dx.doi.org/10.2147/IIN.S94467 (c) (i) (5) $2016 \mathrm{Ju}$ et al. This work is published and licensed by Dove Medical Press Limited. The full terms of this license are available at https://www.dovepress.com/terms.php cc) ${ }_{\mathrm{BY}} \mathrm{NC}$ and incorporate the Creative Commons Attribution - Non Commercial (unported, v3.0) License (http://creativecommons.org/licenses/by-n/3.0/). By accessing the work you hereby accept the Terms. Non-commercial uses of the work are permitted without any further permission from Dove Medical Press Limited, provided the work is properly attributed. For permission for commercial use of this work, please see paragraphs 4.2 and 5 of our Terms (https://www.dovepress.com/terms.php). 
the targeting molecule to promote the penetration of drugs into cancer cells. Moreover, epirubicin and celecoxib were encapsulated into the liposome vesicles to kill the cancer cells and to inhibit the VM channel-forming cells, respectively. The results demonstrated significant efficacy in the treatment of invasive breast cancer.

In the present study, we hypothesized that targeting epirubicin plus celecoxib liposomes could transport across the $\mathrm{BBB}$, treat the brain glioma, and eliminate their VM channels. This idea was based on the recent studies which found that the PTD $_{\text {HIV-1 }}$ peptide could increase the transport of nanoparticles or proteins across the BBB. ${ }^{10,11}$ The likely reason for this ability could be related to the negative charge of the $\mathrm{BBB}$, which can interact with the positively charged PTD $_{\text {HIV-1 }}$ peptide, which can be bonded to liposomes, thereby mediating the adsorptive transport of the drug across the BBB. ${ }^{12}$ Moreover, the BBB is fenestrated or partially damaged during the progression of brain glioma, and there is an enhanced permeability-andretention effect for nanoparticles in the glioma surroundings as well. ${ }^{13}$ As a result, the nanostructured targeting liposomes accumulate more in the brain glioma sites.

The PTD $_{\text {HIV-1 }}$ peptide has an arginine-rich sequence, and it originates from the HIV-1 virus transmembrane proteintransduction domain, which can penetrate biological cell membranes. ${ }^{14}$ The PTD $_{\text {HIV-1 }}$ peptide can mediate the transport of a variety of macromolecules and nanocarriers inward across the cell membrane. ${ }^{15}$ Moreover, the $\mathrm{PTD}_{\mathrm{HIV}-1}$ peptide has a strong affinity with cerebral microvascular endothelial cells (MVECs) on the BBB by electrostatic attraction. ${ }^{16,17}$ The penetration ability and affinity of the PTD $_{\text {HIV-1 }}$ peptide could mediate the transport of PTD $_{\text {HIV-1 }}$ peptide-modified liposomes across the BBB.

Epirubicin is an anthracycline anticancer agent with a broad cancer spectrum. It acts through intercalation with DNA strands, and inhibits the synthesis of DNA and RNA. ${ }^{18}$ In addition, it also triggers DNA cleavage by topoisomerase II and generates free radicals to kill cancer cells. ${ }^{19}$ Epirubicin can be used to treat various extracerebral tumors alone or in combination with other medications, but fails to treat brain glioma as a result of hindrance by the $\mathrm{BBB} .^{20}$

Celecoxib is a COX-2 selective inhibitor that is used for the treatment of inflammations. ${ }^{21}$ Increasing evidence shows that celecoxib could augment chemotherapeutic efficacy via the induction of apoptosis. ${ }^{22}$ In addition, our previous study demonstrated that celecoxib could also inhibit the formation of VM channels in invasive breast cancer. ${ }^{9}$

The objectives of the present study were to characterize the transport ability of targeting epirubicin plus celecoxib liposomes across the BBB, and to assess their efficacy in the treatment of brain glioma and destruction of brain glioma VM channels.

\section{Materials and methods Materials}

Epirubicin hydrochloride and celecoxib were purchased from Nanjing Tianzun Zezhong Chemicals Co Ltd (Nanjing, People's Republic of China). 1,2-Distearoyl-snglycero-3-phosphoethanolamine (DSPE)-polyethylene glycol, molecular weight 2,000 Da $\left(\mathrm{PEG}_{2,000}\right)$ and DSPE$\mathrm{PEG}_{2,000}-N$-hydroxysuccinimide were obtained from NOF Corporation (Tokyo, Japan). The PTD $_{\text {HIV-1 }}$ peptide was synthesized by Shanghai Apeptide Co Ltd (Shanghai, People's Republic of China). Other chemicals were analytical or high-performance liquid-chromatography grade.

Brain glioma U87MG cells were purchased from the Institute of Basic Medical Science at the Chinese Academy of Medical Sciences (Beijing, People's Republic of China). The culture medium was Eagle's minimum essential medium (MEM; Macgene Beijing Biotechnology Ltd, Beijing, People's Republic of China), supplemented with $10 \%$ fetal bovine serum (Thermo Fisher Scientific, Waltham, MA, USA).

Murine brain MVECs (BMVECs) were obtained from the China-Japan Friendship Hospital (Beijing, People's Republic of China). BMVECs were maintained in Dulbecco's Modified Eagle's Medium (high glucose) containing 20\% fetal bovine serum, $100 \mathrm{U} / \mathrm{mL}$ penicillin, $100 \mathrm{U} / \mathrm{mL}$ streptomycin, $2 \mathrm{mmol} / \mathrm{L}$ L-glutamine, $100 \mu \mathrm{g} / \mathrm{mL}$ endothelial cell (EC) growth factor, and $40 \mathrm{U} / \mathrm{mL}$ insulin. The cells were cultured at $37^{\circ} \mathrm{C}$ and $5 \% \mathrm{CO}_{2}$. Male BALB/c nude mice (18-20 g) were obtained from the Peking University Experimental Animal Center (Beijing, People's Republic of China).

The experiments involving human cells and mice were approved by the Ethics Committee of Peking University Health Science Center (Beijing, People's Republic of China).

\section{Preparation of the liposomes}

DSPE-PEG ${ }_{2,000}-\mathrm{PTD}_{\mathrm{HIV}-1}$ conjugate was synthesized, and the targeting epirubicin plus celecoxib liposomes were developed and characterized as in our previous report. ${ }^{9}$ Briefly, egg phosphatidylcholine, cholesterol, DSPE-PEG ${ }_{2,000}$, DSPE-PEG $_{2,000}-\mathrm{PTD}_{\text {HIV-1 }}$, and celecoxib were dissolved in chloroform at a ratio of 70:30:2:3:2.8 ( $\mathrm{mmol} / \mathrm{mmol})$ into a pear-shaped bottle. Then, thin-film rehydration method was used, followed by the ammonium sulfate-gradient method to encapsulate epirubicin.

Free epirubicin, epirubicin liposomes, and epirubicin plus celecoxib liposomes were included as the control formulations. Fluorescence-labeled liposomes were prepared 
by encapsulating coumarin or 1,1-dioctadecyl-3,3,3, 3-tetramethylindotricarbocyanine iodide (DiR) into the bilayer of liposome and used as the fluorescent probes. In all of the liposomal formulations, the encapsulation efficiencies of epirubicin and celecoxib were $>95 \%$ and $>83 \%$, respectively. The average particle size of the targeting liposomes was approximately $108 \mathrm{~nm}$, with a narrow polydispersity index $(\leq 0.20)$ and a nearly neutral potential.

\section{Cellular uptake and targeted localization in brain glioma cells}

To study cellular uptake, brain glioma U87MG cells were seeded into six-well plates at a density of $3 \times 10^{5}$ cells/ well. After incubation for 24 hours, the cells were washed twice with phosphate-buffered saline (PBS; $137 \mathrm{mM} \mathrm{NaCl}$, $2.7 \mathrm{mM} \mathrm{KCl}, 8 \mathrm{mM} \mathrm{Na}_{2} \mathrm{HPO}_{4}$, and $2 \mathrm{mM} \mathrm{KH}_{2} \mathrm{PO}_{4}, \mathrm{pH} 7.4$ ) to remove the remnant growth medium and then incubated in serum-free medium containing free epirubicin, epirubicin liposomes, or targeting epirubicin liposomes at a concentration of $15 \mu \mathrm{M}$ epirubicin. The drug-free culture medium was used as the blank control. After incubation for 4 hours, the cells were washed three times with cold $\mathrm{pH}$ 7.4 PBS and then resuspended in $300 \mu \mathrm{L}$ of $\mathrm{PBS}$ at $\mathrm{pH}$ 7.4. Epirubicin fluorescence signals were measured using a flow cytometer (BD Biosciences, San Jose, CA, USA).

To observe intracellular targeted colocalization, brain glioma U87MG cells were seeded onto chambered coverslips at a density of $1.5 \times 10^{5}$ cells/well. After incubation for 24 hours, the cells were treated with epirubicin liposomes or targeting epirubicin liposomes at a concentration of $20 \mu \mathrm{M}$ epirubicin for another 2 hours. The cells were then washed with cold $\mathrm{pH}$ 7.4 PBS three times, fixed with 4\% paraformaldehyde for 10 minutes, and stained with Hoechst $33258(2 \mu \mathrm{g} / \mathrm{mL})$ for another 10 minutes. Finally, the cells were imaged and analyzed using a confocal laser-scanning fluorescence microscope (Leica Microsystems, Wetzlar, Germany).

\section{Cytotoxicity to brain glioma cells}

To evaluate the cytotoxic effect of targeting epirubicin plus celecoxib liposomes, brain glioma U87MG cells were seeded at a density of $8 \times 10^{3}$ cells/well in 96-well culture plates and cultured for 24 hours. The cells were then treated with celecoxib liposomes, epirubicin liposomes, epirubicin plus celecoxib liposomes, or targeting epirubicin plus celecoxib liposomes. Both concentrations of epirubicin and celecoxib were in the range of $0-5 \mu \mathrm{M}$ (epirubicin:celecoxib 1:1 $\mu \mathrm{M} / \mu \mathrm{M}$ ). After incubation for another 48 hours, the cytotoxic effect was observed with a sulforhodamine B (SRB) colorimetric assay. ${ }^{23}$ Briefly, the culture medium was discarded, and then the cells were fixed with trichloroacetic acid, followed by staining with SRB. Absorbance values were measured at $540 \mathrm{~nm}$ using a microplate reader (Infinite F50; Tecan Trading AG, Männedorf, Switzerland). The survival ratios were calculated using the following formula:

$$
\text { Survival rate } \%=\frac{\mathrm{A}_{540 \mathrm{~nm}} \text { for treated cells }}{\mathrm{A}_{540 \mathrm{~nm}} \text { for control cells }} \times 100 \%
$$

where $A_{540 \mathrm{~nm}}$ represents the absorbance value.

\section{Transport ability across the BBB}

To evaluate the transport ability across the $\mathrm{BBB}$, the in vitro BBB model was established as described previously. ${ }^{24}$ Briefly, BMVECs were seeded onto gelatin solution-coated transwells $\left(0.4 \mu \mathrm{M}\right.$ pore size, $12 \mathrm{~mm}$ diameter, and $1.12 \mathrm{~cm}^{2}$ surface area; Corning Incorporated, Corning, NY, USA) at a density of $1 \times 10^{4}$ cells/well and incubated for 6 days. The culture medium was changed every other day. During the experiment, the tightness of the established BBB model was evaluated by measuring the transepithelial electrical resistance (TEER) values. Once the TEER values were higher than $200 \Omega \cdot \mathrm{cm}^{2}$, the BBB model was applied for experiments. Brain glioma U87MG cells were seeded at the bottom of a 12-well culture plate under a transwell at a density of $2 \times 10^{4}$ cells/ well. To evaluate the transport ratio of drug-loaded liposomes across the BBB, varying liposomal formulations were added to the transwells at a concentration of $10 \mu \mathrm{M}$ epirubicin. After incubation for 4 hours, the inserts were moved away, and brain glioma U87MG cells were further incubated for 24 hours. The procedures following that were the same as those used in the SRB assay. The transport ability of drugloaded liposomes across the BBB model was evaluated by measuring the survival ratio of brain glioma cells in the lower compartment under the BBB insert.

\section{Induction of apoptosis in brain glioma cells and the underlying mechanism}

To evaluate the apoptosis-inducing effect of targeting epirubicin plus celecoxib liposomes, brain glioma U87MG cells were seeded in six-well plates at a density of $3 \times 10^{5}$ cells/ well and cultured for 24 hours. Drug administrations were then carried out as described earlier at a concentration of $10 \mu \mathrm{M}$ epirubicin. After further incubation for 6 hours, the cells were harvested and stained with Sytox Green (Thermo Fisher Scientific) and Annexin V-KeyFluor 647 (KeyGen Biotech Co Ltd, Nanjing, People's Republic of China) according to the manufacturer's protocol. After being stained, 
the glioma cells were quantified within 1 hour by flow cytometry (Gallios; BD Biosciences).

To investigate the apoptotic mechanism, apoptotic enzymes and proteins were measured after brain glioma U87MG cells were treated with varying drug formulations. Briefly, brain glioma U87MG cells were grown to $50 \%$ confluence in 96-well plates before treatment with epirubicin liposomes $(10 \mu \mathrm{M})$, epirubicin plus celecoxib liposomes (both drugs at $10 \mu \mathrm{M}$ ), and targeting epirubicin plus celecoxib liposomes (both drugs at $10 \mu \mathrm{M}$ ). Serum-free MEM was added as a blank control. After incubation for 6 hours, the cells were fixed with $4 \%$ formaldehyde for 15 minutes. Then, the cells were permeabilized with pH 7.4 PBS containing $0.5 \%$ Triton X-100 and $0.3 \mathrm{M}$ glycine for 15 minutes and blocked with pH 7.4 PBS containing 5\% goat serum for 2 hours at room temperature. The cells were then incubated with primary antibodies (anti-caspase-3, anti-caspase-8, antiBax, and anti-Mcl-1; Sangon Biotech, Shanghai, People's Republic of China). All of the primary antibodies were diluted to $2 \mu \mathrm{g} / \mathrm{mL}$ and incubated at $4^{\circ} \mathrm{C}$ overnight.

The culture wells were added with antirabbit or antimouse secondary antibody conjugated with Alexa Fluor 488 (1:500; OriGene Technologies Inc, Rockville, MD, USA) and further incubated for 2 hours at room temperature. Cell nuclei in these culture wells were then counterstained with Hoechst $33258(2 \mu \mathrm{g} / \mathrm{mL})$ for 10 minutes. The fluorescence intensity of each well was subsequently measured using the Operetta high-content screening system (PerkinElmer Inc, Waltham, MA, USA).

\section{Penetration into the brain glioma spheroids}

To mimic the penetrating ability during the treatment of solid brain glioma, multicellular glioma spheroids were established using the liquid-overlay system by incorporating brain glioma U87MG cells. ${ }^{25}$ Briefly, agarose was added to serum-free MEM culture and heated to $80^{\circ} \mathrm{C}$ for 30 minutes to form $2 \%(\mathrm{w} / \mathrm{v})$ solution. Each well of the 48 -well culture plates was coated with a thin layer $(100 \mu \mathrm{L})$ of the agarose solution. After the culture plates had been cooled to room temperature, brain glioma U87MG cells were seeded into culture plates at $2 \times 10^{3}$ cells/well with $100 \mu \mathrm{L}$ culture medium. Culture plates were then gently shaken for 2 minutes to balance glioma cells and incubated for 48 hours to form glioma spheroids. To evaluate penetration ability, targeting coumarin liposomes were used as a fluorescent probe. Briefly, the glioma spheroids were treated with free coumarin, coumarin liposomes, or targeting coumarin liposomes at a concentration of $10 \mu \mathrm{M}$ coumarin and incubated for 12 hours at $37^{\circ} \mathrm{C}$ and $5 \% \mathrm{CO}_{2}$. The spheroids were then washed with $\mathrm{pH}$ 7.4 PBS and scanned at the different layers from the top to the inside of the spheroids using a confocal laser-scanning fluorescence microscope.

\section{Destruction of VM channels in vitro and the mechanism}

To evaluate the destructive effect of targeting epirubicin plus celecoxib liposomes, the VM channels of brain glioma were established using a Matrigel-based formation method. ${ }^{26}$ Briefly, 96-well culture plates were first coated with Matrigel $(50 \mu \mathrm{L} /$ well $)$ and allowed to agglutinate at $37^{\circ} \mathrm{C}$ for 30 minutes. Then, brain glioma U87MG cells were seeded into the culture plates at a density of $10^{4}$ cells/well in serumfree MEM. Free celecoxib $(1,5$, and $10 \mu \mathrm{M})$, celecoxib liposomes $(10 \mu \mathrm{M})$, targeting celecoxib liposomes $(10 \mu \mathrm{M})$, and targeting epirubicin plus celecoxib liposomes $(5 \mu \mathrm{M})$ were separately added into the culture system. Blank medium was used as a control. After incubation for 12 hours, each well was photographed and analyzed using an Evos microscope (Thermo Fisher Scientific).

To study the action mechanism, six protein indicators involved in the formation of the VM channels (MMP-2, MMP-9, VE-Cad, FAK, PI3K, and VEGF) in cancer cells were determined using enzyme-linked immunosorbent assay kits (Cusabio Biotech Co Ltd, Beijing, People's Republic of China). Briefly, brain glioma cells were cultured to $80 \%$ confluence and then treated with celecoxib liposomes, epirubicin liposomes, epirubicin plus celecoxib liposomes, and targeting epirubicin plus celecoxib liposomes at a concentration of 5 $\mu \mathrm{M}$ celecoxib or $5 \mu \mathrm{M}$ epirubicin. Culture medium was used as a blank control. After incubation for 12 hours, the cells were harvested and lysed. The cell lysates were analyzed using a microplate reader according to the manufacturers' instructions. The protein-activity ratio was calculated using the following formula:

$\underset{\text { ratio } \%}{\text { Activity }}=\frac{\mathrm{A}_{450 \mathrm{~nm}} \text { for treated cells } / \mathrm{A}_{562 \mathrm{~nm}} \text { for treated cells }}{\mathrm{A}_{450 \mathrm{~nm}} \text { for control cells } / \mathrm{A}_{562 \mathrm{~nm}} \text { for control cells }}$

where $A_{450 \mathrm{~nm}}$ and $\mathrm{A}_{562 \mathrm{~nm}}$ represent the absorbance values.

\section{In vivo distribution and treatment efficacy in brain glioma-bearing mice}

To evaluate in vivo distribution and anticancer efficacy, a brain glioma-bearing mouse model was established by 
intracranial implantation. A total of 55 male $\mathrm{BALB} / \mathrm{c}$ nude mice (18-20 g) were included for the study. All of the procedures were performed according to the guidelines of the Institutional Authority for Laboratory Animal Care of Peking University. Briefly, the nude mice were anesthetized by $4 \%$ chloral hydrate $(10 \mu \mathrm{L} / \mathrm{g})$ and incised through the skin to expose the cranium. The coordinates of the inoculation point was set at $1 \mathrm{~mm}$ anterior from the coronal suture, $3.5 \mathrm{~mm}$ right lateral from the sagittal suture, and $3 \mathrm{~mm}$ in depth. A volume of $3 \mu \mathrm{L}$ of brain glioma U87MG cells $\left(1 \times 10^{5}\right.$ cells $\left./ \mu \mathrm{L}\right)$ were implanted into the inoculation point of each nude mouse, using a stereotaxic instrument (RWD Life Science Co Ltd, Shenzhen, People's Republic of China).

\section{Imaging the distribution in vivo}

To evaluate in vivo drug distribution in the brain glioma site after treatment, targeting DiR liposomes were intravenously administered as the fluorescent probe. Briefly, 12 male nude mice were inoculated in situ with brain glioma U87MG cells as earlier. After inoculation, on day 14 the mice were randomly divided into four groups and administered physiological saline, free DiR, DiR liposomes, and targeting DiR liposomes via the tail vein at a dose of $1 \mu \mathrm{g}$ DiR per mouse. Fluorescent images and X-ray images were captured using an in vivo imaging system (Carestream FX Pro; Bruker Corporation, Billerica, MA, USA) at varying time points $(2,6,12,24$, and 48 hours). The nude mice were then killed by cervical dislocation at 48 hours to collect brains, hearts, livers, spleens, lungs, and kidneys. The fluorescent images and X-ray images were also captured for all ex vivo tissues.

\section{Survival curves and destruction of VM channels in vivo}

To study overall treatment efficacy, the mice were randomly divided into five groups (eight nude mice/group) on day 10 postinoculation. Physiological saline, free epirubicin, epirubicin liposomes, epirubicin plus celecoxib liposomes, and targeting epirubicin plus celecoxib liposomes were administered to mice via the tail vein at a dose of $5 \mathrm{mg} / \mathrm{kg}$ epirubicin (epirubicin:celecoxib 1:1 $\mu \mathrm{M}$ in celecoxib-containing formulations). Treatments were made every other day four consecutive times. The survival of the mice was observed, and the survival curve was made accordingly.

To study the destruction of VM channels in vivo, brain tissues were collected from the killed mice during survival investigation, and the frozen slices ( $10 \mu \mathrm{m}$ in thickness) of the tissues were prepared. Afterward, CD34 endothelial marker periodic acid-Schiff (PAS) dual staining was performed on the slices. ${ }^{27}$ Briefly, monoclonal anti-CD34 (Santa Cruz Biotechnology Inc, Dallas, TX, USA) was used for staining the slices at a dilution of 1:300 (v/v). After immunohistochemical staining, the slices were exposed to $1 \%$ sodium periodic acid for 10 minutes. Then, the slices were incubated with PAS for 2 minutes and finally counterstained with hematoxylin. The images were photographed using the Evos microscope.

\section{Toxicity evaluation of the organs}

To evaluate potential toxicity after treatment with different formulations, the heart, liver, spleen, lung, and kidney tissues were removed from killed mice during survival investigations. The tissues were fixed in $10 \%$ formalin, decalcified in $10 \%$ ethylenediaminetetraacetic acid-disodium, embedded in paraffin, and then stained with hematoxylin and eosin. Toxic effects on major organs were assessed under light microscopy according to a standard protocol. ${ }^{28}$

\section{Statistical analysis}

Data are presented as mean \pm standard deviation. One-way analysis of variance was used to determine the significance among groups, after which post hoc tests with Bonferroni correction were used for multiple comparisons between individual groups. A value of $P<0.05$ was considered significantly different.

\section{Results \\ Cellular uptake and targeted localization in brain glioma cells}

After treatment with varying drug formulations, the fluorescence intensity in brain glioma U87MG cells measured by flow cytometry demonstrated that the targeting epirubicin liposomes were internalized more than the epirubicin liposomes. In addition, brain glioma cells evidently ingested free epirubicin (Figure 1A). In the semiquantitative flowcytometry evaluation, the rank of cellular uptake was free epirubicin $>$ targeting epirubicin liposomes $>$ epirubicin liposomes $>$ blank medium (Figure 1B).

Results from confocal laser-scanning fluorescence microscopy showed that the red fluorescent signal of targeting epirubicin liposomes was significantly brighter than that of epirubicin liposomes after treatment (Figure 1C and D). In addition, targeting epirubicin liposomes showed an obvious affinity for the cellular membrane and cellular nuclei in the brain glioma U87MG cells. 

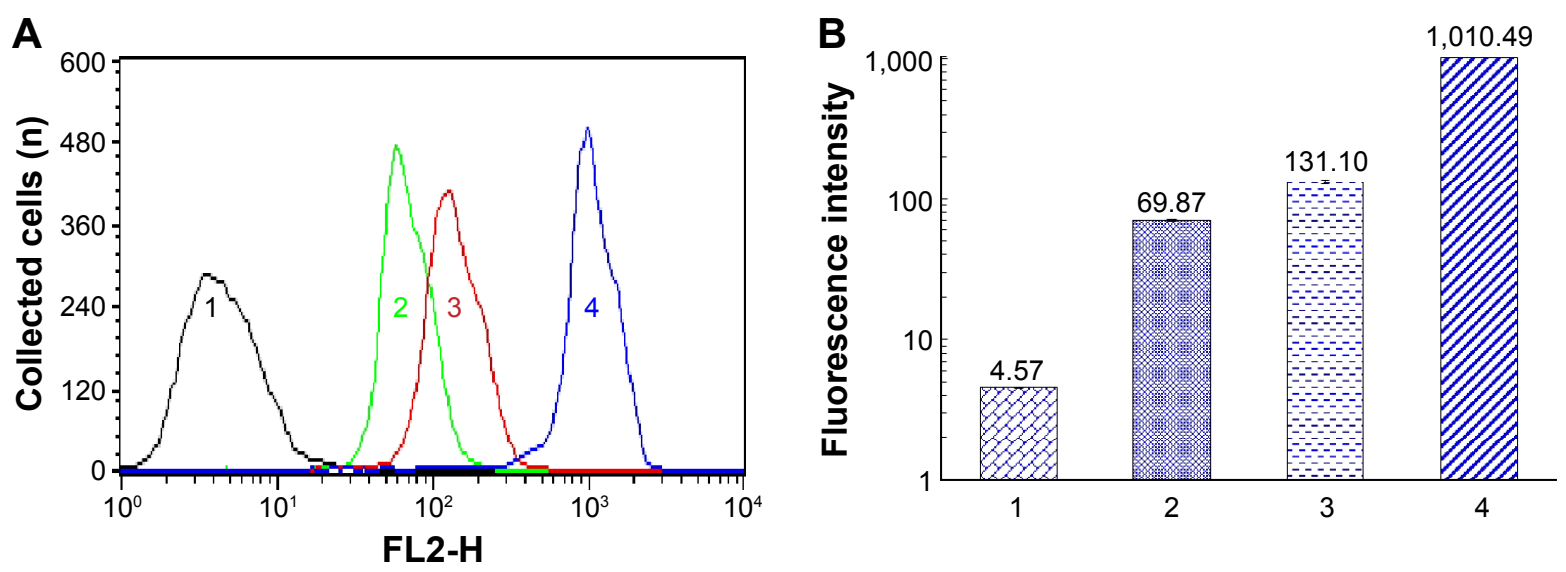

$\begin{array}{llll}\text { 1. Blank control } & \text { 2. Epirubicin liposomes } & \text { 3. Targeting epirubicin liposomes } \quad \text { 4. Free epirubicin }\end{array}$
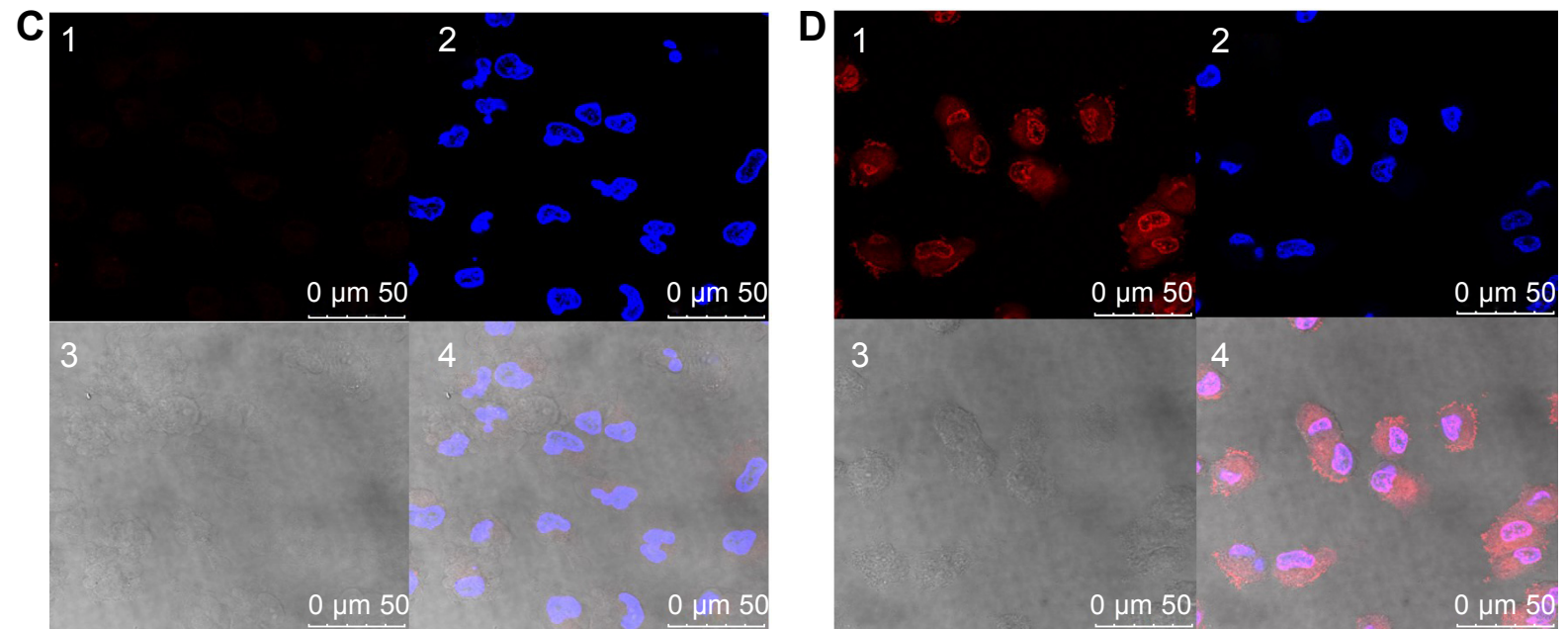

Figure I Cellular uptake and targeted localization in brain glioma cells after incubation with targeting epirubicin liposomes.

Notes: $\mathbf{A}$ and $\mathbf{B}$ indicate the results of cellular uptake by flow cytometry. The targeted localization of epirubicin liposomes (C) and targeting epirubicin liposomes (D) by confocal laser scanning fluorescent microscopy. $\mathbf{C I}$ and $\mathbf{D I}$ show the fluorescence signals of epirubicin from epirubicin and targeting epirubicin liposomes, respectively. The fluorescent intensity of $\mathbf{C l}$ was obviously weaker than that of DI, indicating lower cellular uptake. C2 and D2 show the nuclei which were dyed by Hoechst. C3 and D3 show the bright light fields of brain glioma cells (without fluorescence). C4 and D4 show the overlapped images of CI-3 and DI-3, respectively.

\section{Cytotoxicity to brain glioma cells}

The results from the cytotoxicity assay showed that the targeting epirubicin plus celecoxib liposomes demonstrated the strongest cytotoxic effect on brain glioma cells (Figure 2). Furthermore, lower concentrations of celecoxib liposomes alone $(0-5 \mu \mathrm{M})$ exerted slight cytotoxic effects on brain glioma cells, while epirubicin plus celecoxib liposomes had a significantly stronger cytotoxic effect than that of epirubicin liposomes, indicating augmented efficacy by celecoxib.

\section{Transport ability across the BBB}

The BBB was able to be formed after incubation with BMVECs in the upper inserts of the transwells for 6 days. The TEER values of the BBB reached 220-260 $\Omega \cdot \mathrm{cm}^{2}$, and $\mathrm{BBB}$ integrity was maintained during the experiment (Figure 3A).

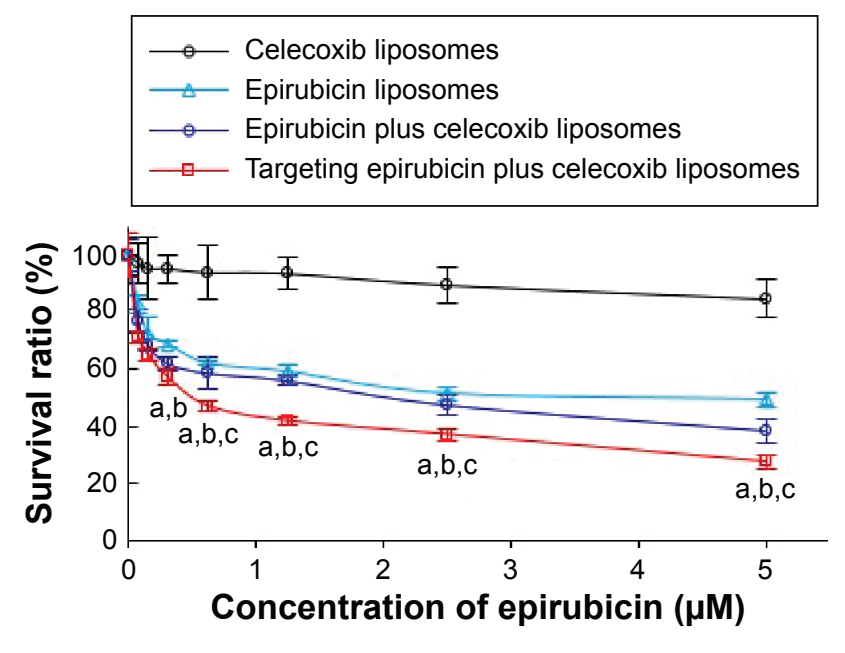

Figure 2 Cytotoxicity to brain glioma U87MG cells after treatment with targeting epirubicin plus celecoxib liposomes.

Notes: $P<0.05$. a, vs celecoxib liposomes; b, vs epirubicin liposomes; c, vs epirubicin plus celecoxib liposomes. Data presented as mean \pm standard deviation $(n=6)$. 

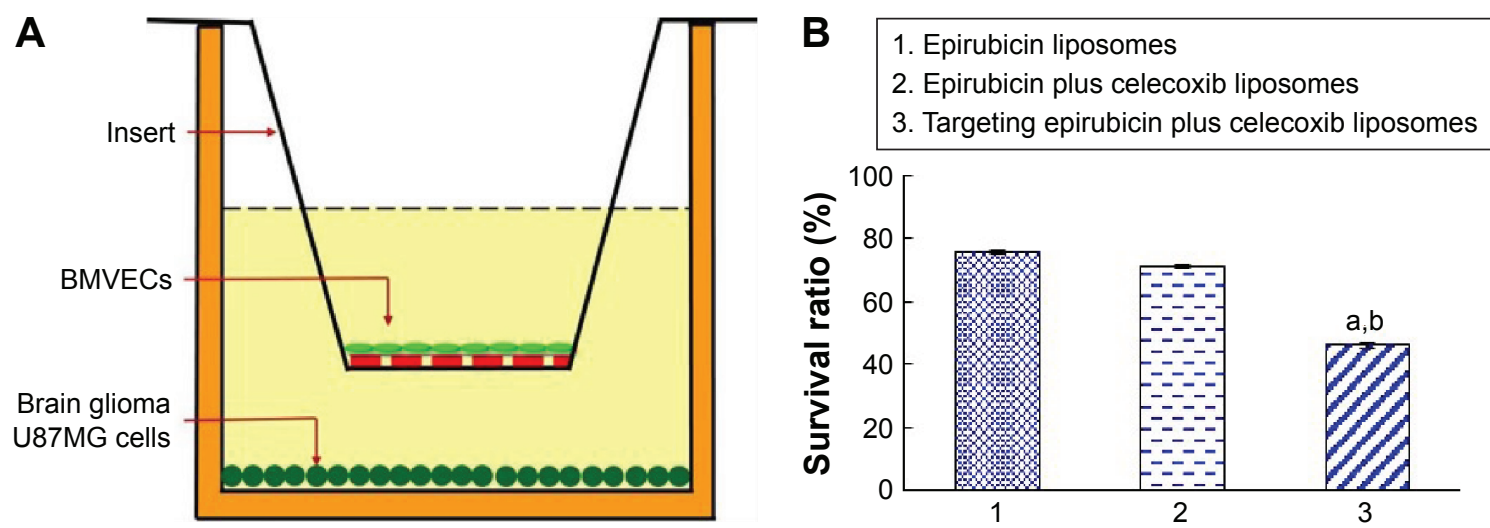

Figure 3 Transport ability of targeting epirubicin plus celecoxib liposomes across the BBB model.

Notes: (A) Schematic representation of the BBB model. (B) Transport ability, indicated by the death of brain glioma cells after drug transport across the BBB. $P<0.05$. a, vs I; b, vs 2. Data presented as mean \pm standard deviation $(n=3)$.

Abbreviations: BBB, blood-brain barrier; BMVECs, brain microvascular endothelial cells.

The transport ability of targeting epirubicin plus celecoxib liposomes was evidenced by the inhibitory effect on brain glioma U87MG cells after transport across the BBB. The results showed that the survival rate rank of brain glioma cells was targeting epirubicin plus celecoxib liposomes $<$ epirubicin plus celecoxib liposomes $<$ epirubicin liposomes (Figure 3B), demonstrating strongest transport ability for the targeting drug-loaded liposomes across the BBB, followed by a killing effect on brain glioma cells.

\section{Induction of apoptosis in brain glioma cells and the underlying mechanism}

After incubation with varying formulations for 4 hours, the average rate of apoptosis in brain glioma U87MG cells was $3.16 \% \pm 0.21 \%$ for epirubicin liposomes, $4.47 \% \pm 0.59 \%$ for epirubicin plus celecoxib liposomes, and $29.35 \% \pm 1.22 \%$ for targeting epirubicin plus celecoxib liposomes (Figure 4A). The results demonstrated that the targeting epirubicin plus celecoxib liposomes had the strongest apoptosis-inducing effect on brain glioma cells compared to the controls.

The results from the fluorescence images by the highcontent screening system showed that the nuclei of brain glioma cells were stained blue by Hoechst 33258, while activated apoptotic enzymes or proteins were stained green by their specific monoclonal antibodies. Upon assessment of fluorescence intensities, the expression of caspase-8, caspase-3, and Bax was significantly increased after treatment with varying formulations, among which targeting epirubicin plus celecoxib liposomes demonstrated the strongest activating effect on proapoptotic enzymes or proteins. In contrast, expression of the antiapoptotic protein Mcl-1 was significantly decreased by the drug treatments (Figure 4B).

\section{Penetration into the brain glioma spheroids}

After incubation for 48 hours, the brain glioma spheroids were grown as spheres with an average size of $200-300 \mu \mathrm{m}$ in diameter. After viewing the fluorescence intensity in each layer of the glioma spheroids, results from the confocal observations showed that the rank of penetration ability was targeting coumarin liposomes $>$ free coumarin $\geq$ coumarin liposomes (Figure 5).

\section{Destruction of VM channels in vitro and the underlying mechanism}

Brain glioma U87MG cells readily formed VM channels, which displayed tube networks in three-dimensional (3-D) Matrigel. After treatment with free celecoxib alone, the VM channels were significantly inhibited in a celecoxib concentration-dependent manner. After treatment with different formulations, the rank of the destructive effect on the VM channels was targeting epirubicin plus celecoxib liposomes $>$ targeting celecoxib liposomes $>$ celecoxib liposomes (Figure 6).

The expression of the VM-channel indicators was evaluated on brain glioma U87MG cells. After treatment with celecoxib liposomes, epirubicin liposomes, epirubicin plus celecoxib liposomes, and targeting epirubicin plus celecoxib liposomes, the expression of MMP-2, MMP-9, VE-Cad, FAK, PI3K, and VEGF was significantly inhibited in brain glioma cells (Figure 7A-C, E, and F). However, the drug treatment hardly affected the expression of PI3K (Figure 7D). In a comparison of the effects among the different formulations, the targeting epirubicin plus celecoxib liposomes exhibited the most significant inhibitory effects on these indicators. 


\section{A}

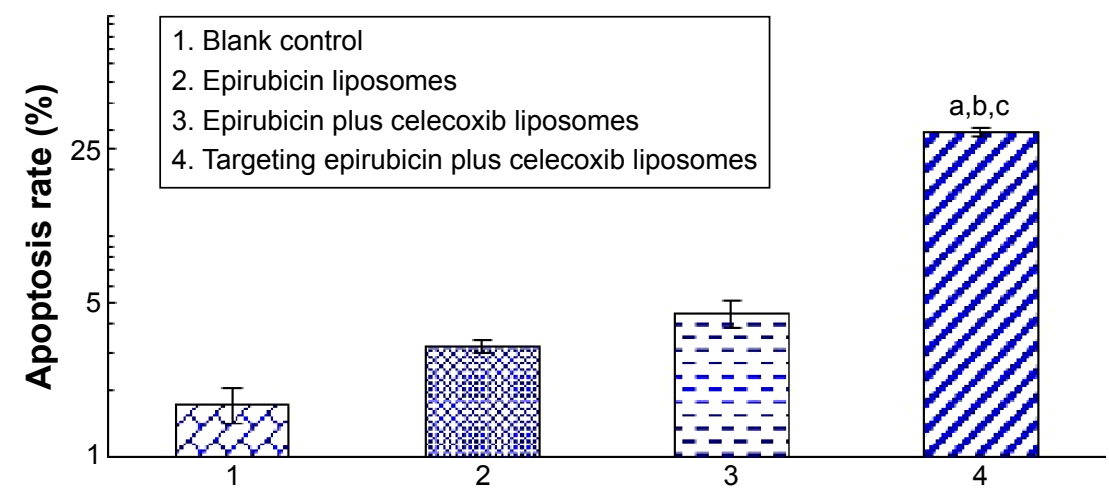

B

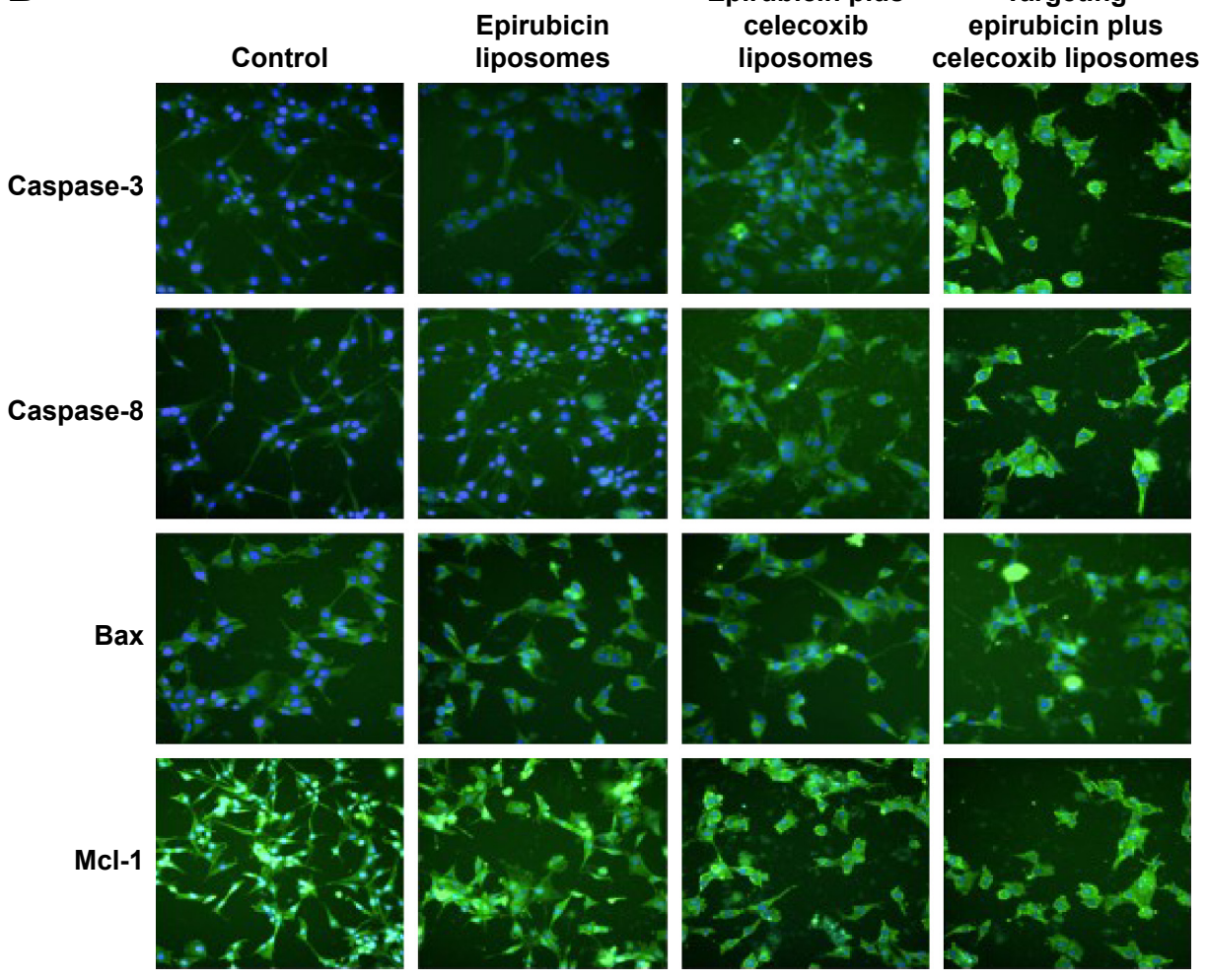

Figure 4 Induction of apoptosis of brain glioma cells and mechanism after treatment with targeting epirubicin plus celecoxib liposomes.

Notes: (A) Induction of apoptosis in brain glioma. a, vs I; b, vs 2; c, vs 3. (B) Expression changes of enzymes or proteins involved in apoptotic signaling pathways. The intensity of green fluorescence captured by the high content screening system indicates that the expressions of caspase-8, caspase-3, and Bax were enhanced, while the expression of Mcl-I was decreased, after drug treatments. Images were obtained under a microscope at $80 \times$ magnification.

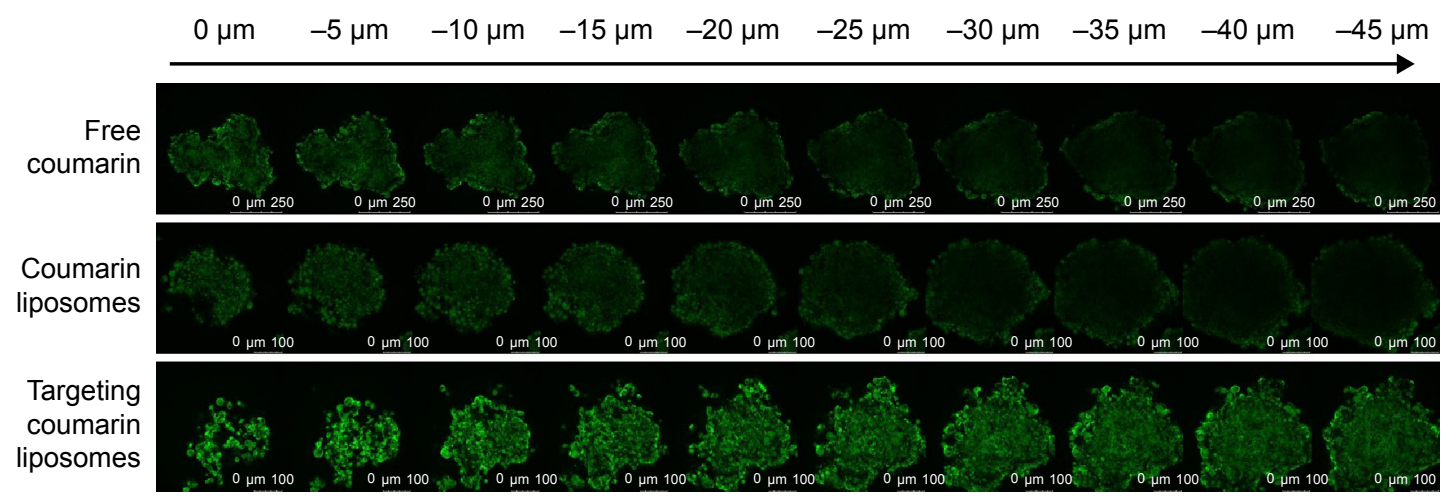

Figure 5 Penetration into brain glioma spheroids (indicated with arrow) after treatment with targeting coumarin liposomes.

Note: Results indicate that the targeting coumarin liposomes exhibit the strongest penetration into the brain glioma spheroids. 

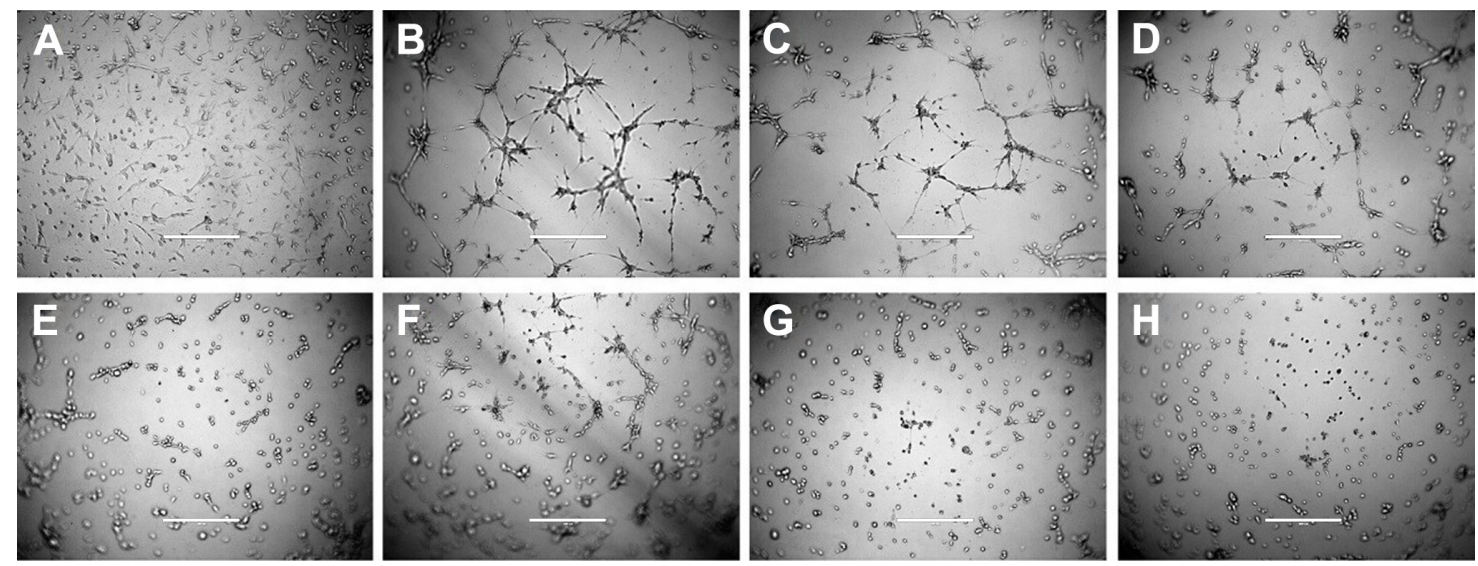

Figure 6 Destruction of VM channels in vitro formed by brain glioma U87MG cells in the 3-D Matrigel after treatment with targeting epirubicin plus celecoxib liposomes. Notes: (A) Brain glioma cells without Matrigel. (B) Brain glioma VM channels formed in the 3-D Matrigel without treatment. (C-E). Destruction of VM channels after treatment with a fixed concentration of free celecoxib (I, 5, and $10 \mu \mathrm{M}$, respectively). (F) Destruction of VM channels after treatment with celecoxib liposomes (I0 $\mu \mathrm{M})$. (G) Destruction of VM channels after treatment with targeting celecoxib liposomes (I0 $\mu \mathrm{M})$. (H) Destruction of VM channels after treatment with targeting epirubicin plus celecoxib liposomes (5 $\mu$ M epirubicin and $5 \mu$ M celecoxib). The scale bars in $\mathbf{A}-\mathbf{H}$ indicate $400 \mu \mathrm{m}$.

Abbreviations: VM, vasculogenic mimicry; 3-D, three-dimensional.
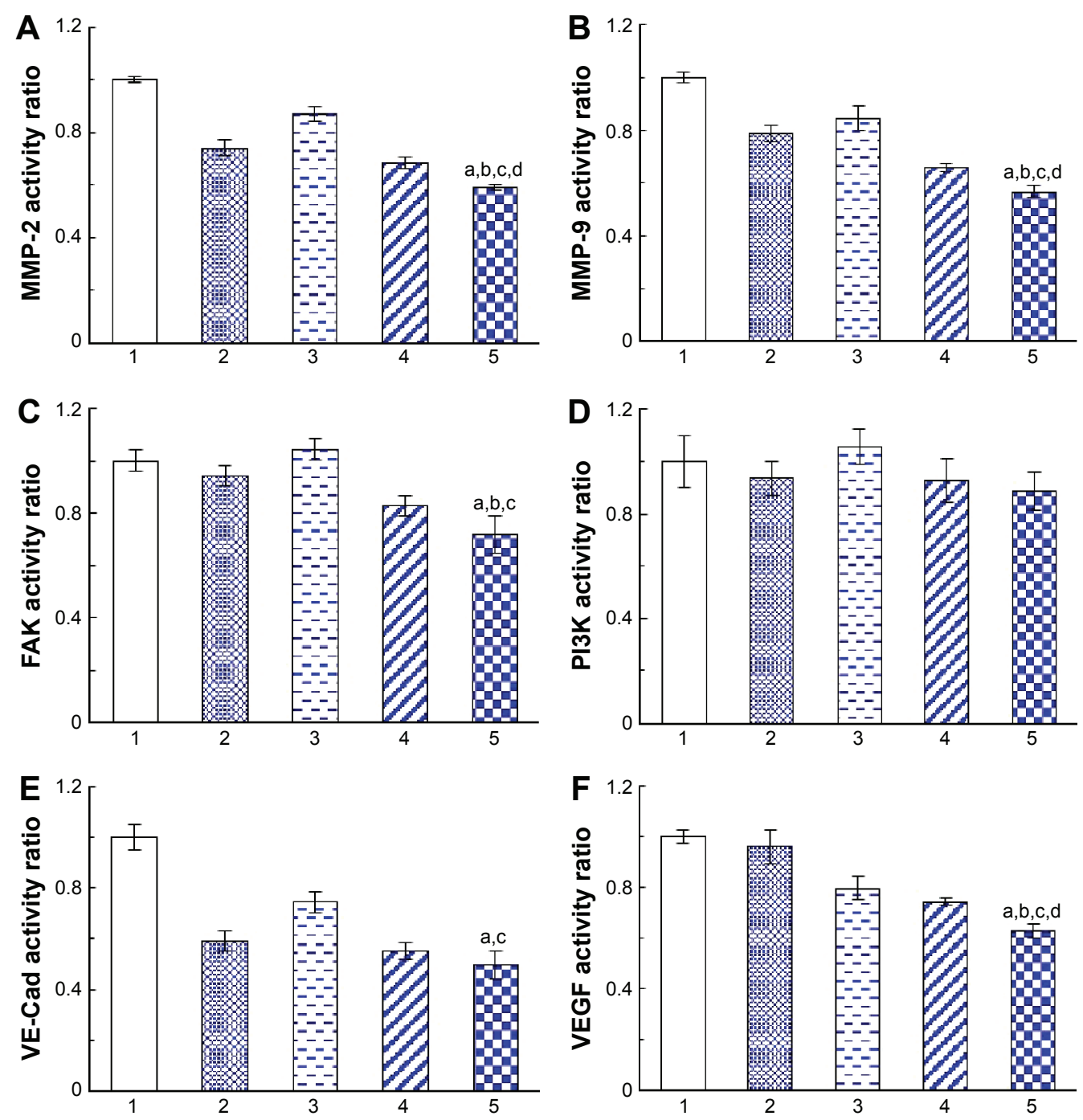

Figure 7 Inhibition of the VM indicators in brain glioma cells after treatment with targeting epirubicin and celecoxib liposomes.

Notes: (A) Activity ratios of MMP-2. (B) Activity ratios of MMP-9. (C) Activity ratios of FAK. (D) Activity ratios of PI3K. (E) Activity ratios of VE-Cad. (F) Activity ratios of VEGF. I, Blank control; 2, celecoxib liposomes; 3, epirubicin liposomes; 4, epirubicin plus celecoxib liposomes; 5 , targeting epirubicin plus celecoxib liposomes. P<0.05. a, vs I; b, vs 2; c, vs 3; d, vs 4 . Data presented as mean \pm standard deviation $(n=4)$.

Abbreviation: VM, vasculogenic mimicry. 


\section{In vivo distribution and treatment efficacy} in brain glioma-bearing mice

Imaging the distribution in vivo

After administration of targeting DiR liposomes, a strong fluorescent signal was observed in the blood circulation and in the brain glioma site (Figure 8A). Furthermore, the fluorescent signal of the targeting DiR liposomes was maintained up to 48 hours in the brain glioma location. After administration of DiR liposomes, the fluorescent signal was also found in the blood circulation and in the brain until 24 hours. In contrast, after administration of free DiR, the fluorescent signal was mainly observed in the liver tissues of the mice.

After administration of targeting DiR liposomes at 48 hours, the fluorescent signal could be observed in the ex vivo brain, liver, and spleen tissues. However, after administration of free DiR or DiR liposomes at 48 hours, the fluorescent signal could only be observed in the ex vivo liver and spleen tissues (Figure 8B).

\section{Survival curves and destruction of $\mathrm{VM}$ channels in vivo}

Kaplan-Meier survival curves of brain glioma-bearing nude mice were obtained by recording the survival days of each mouse after inoculation (Figure 9A). Results showed that the mice treated with targeting epirubicin plus celecoxib liposomes had the longest survival time. The median survival time of brain glioma-bearing mice was 19 days for physiological saline, 21 days for free epirubicin, 25 days for epirubicin liposomes, 26 days for epirubicin plus celecoxib liposomes, and 30 days for targeting epirubicin plus celecoxib liposomes (Table 1).

The destruction of VM channels was evaluated using CD34-PAS dual staining on the brain glioma slices. The VM channels were stained red on slices of brain tissues (Figure 9B). Based on the diminished VM numbers under the microscope, the destructive effects on VM channels were evidenced after drug treatments. Compared to free epirubicin, epirubicin liposomes or epirubicin plus celecoxib liposomes, targeting epirubicin plus celecoxib liposomes had the most significant destructive effect on the in vivo VM channels in the brain glioma-bearing nude mice.

\section{Toxicity evaluation of the organs}

Toxicity to the major organs was evaluated using hematoxylin and eosin staining of their paraffin sections. Compared to the blank control, targeting epirubicin plus celecoxib liposomes did not cause obvious damage to the major organs, which consisted of the heart, liver, spleen, lung, and kidney (Figure 10).

\section{Discussion}

Brain glioma usually exhibits a high recurrence rate after comprehensive treatment, and glioma cells can readily invade peripheral normal tissues. During this process, the residual glioma cells can form VM channels under conditions of hypoxia to support the continuous growth of the brain glioma. The VM channels further develop to become neovasculatures with the participation of ECs, and the neovascularization facilitates the growth of brain glioma cells, leading to the deterioration of the disease. However, current antiangiogenesis therapy is not capable of eradicating VM channels. Therefore, the destruction of VM channels remains an unsolved technical problem. Furthermore, regular chemotherapy has limited efficacy in the treatment of brain glioma, due to hindrance by the BBB. In the present study, targeting liposomes incorporating epirubicin and celecoxib were transferred across the BBB and destroyed the VM channels and brain glioma cells. Our effort was aimed at developing a new chemotherapy strategy in the treatment of brain glioma.

The result from cellular uptake by semiquantitative flow cytometry demonstrates that the targeting epirubicin liposomes significantly enhanced cellular internalization compared to that of unmodified epirubicin liposomes (Figure 1A and B). The action mechanism could be related to the targeting molecule $\mathrm{PTD}_{\text {HIV-1 }}$ peptide, which increased the affinity by electrostatic attraction between the targeting liposomes and the cell membranes and mediated the inward penetration into the cells via both clathrin-dependent endocytosis and heparan sulfate receptor-related transport. A targeted localization after treatment with the targeting liposomes was further observed under confocal microscopy (Figure 1C and D). The result reveals that the targeting epirubicin liposomes could be target-localized to the nuclei, and this would be beneficial for the action of epirubicin in the nuclei of brain glioma cells.

The cytotoxicity observed in brain glioma cells showed that the celecoxib liposomes alone at a low concentration exhibited a weaker inhibitory effect on the cells, but potentiated the anticancer efficacy of epirubicin liposomes, indicating an augmented effect (Figure 2). Furthermore, targeting molecule PTD $_{\text {HIV-1 }}$ peptide modified liposomes by incorporating epirubicin with celecoxib further enhanced the inhibitory effect, demonstrating strong anticancer efficacy. Cytotoxicity revealed three lines of evidence that indicated epirubicin is able to effectively destroy brain glioma cells in vitro, although it fails to treat brain glioma clinically. Celecoxib has a significant augmenting effect on epirubicin, 
A

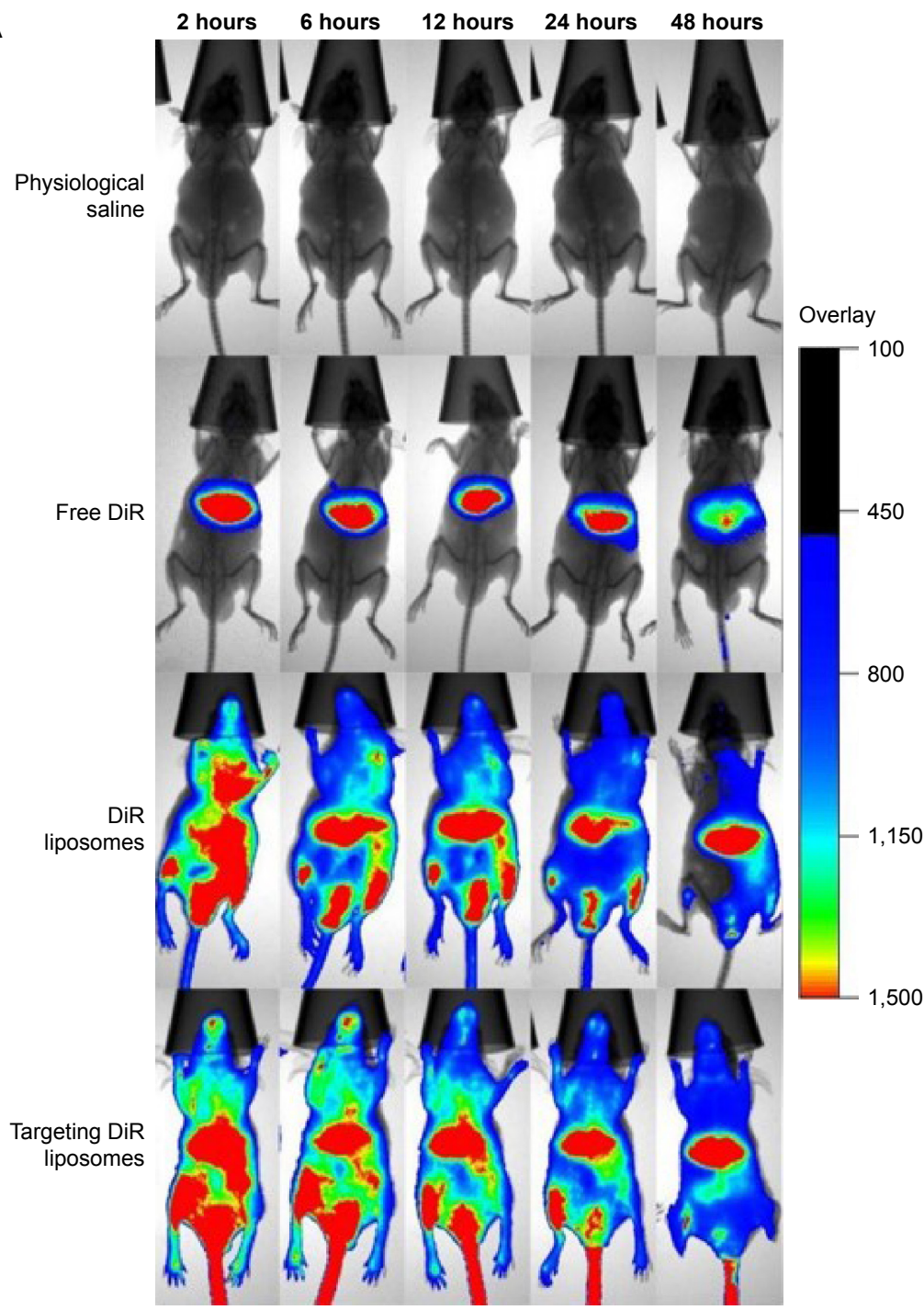

B

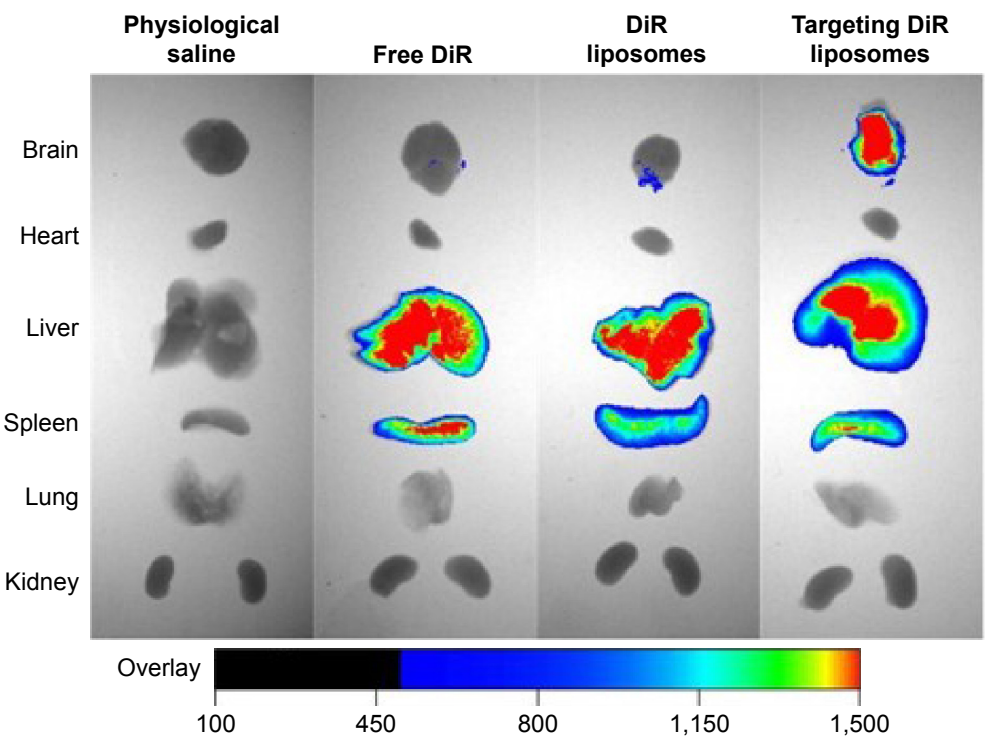

Figure 8 Imaging of distribution in the intracranial glioma-bearing nude mice after intravenous administration of targeting DiR liposomes.

Notes: (A) In vivo real-time imaging of distributions of different formulations within 48 hours. (B) Ex vivo imaging of distributions of different formulations in brain tissues and major organs after mice were killed at 48 hours.

Abbreviation: DiR, I,I-dioctadecyl-3,3,3,3-tetramethylindotricarbocyanine iodide. 

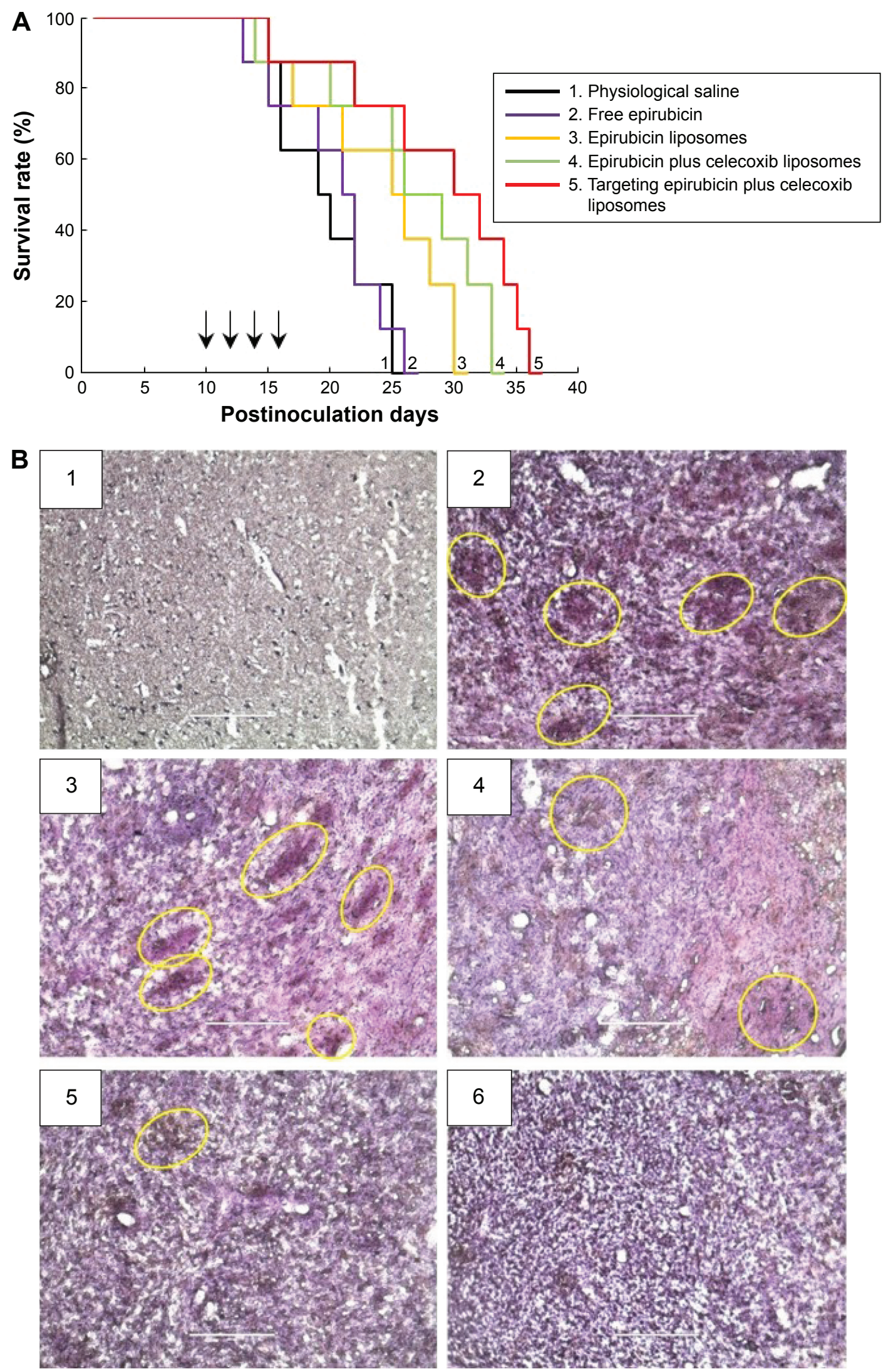

Figure 9 Anticancer efficacy and destruction of VM channels in intracranial glioma-bearing nude mice.

Notes: (A) Kaplan-Meier survival curves. Arrows indicate the administration days. (B) Destruction of VM channels in the intracranial glioma-bearing nude mice using CD34PAS dual staining. The scale bars indicate $200 \mu \mathrm{m}$. (BI) Normal brain tissue. (B2) Physiological saline. (B3) Free epirubicin. (B4) Epirubicin liposomes. (B5) Epirubicin plus celecoxib liposomes. (B6) Targeting epirubicin plus celecoxib liposomes. The yellow circles indicate the in vivo VM channels.

Abbreviation: VM, vasculogenic mimicry. 
Table I Survival time and percentage-increased life span (ILS\%) of glioma-bearing nude mice treated with targeting epirubicin plus celecoxib liposomes

\begin{tabular}{|c|c|c|c|c|c|}
\hline \multirow[t]{2}{*}{ Treatment groups } & \multicolumn{3}{|c|}{ Survival (days) } & \multicolumn{2}{|l|}{ ILS\% } \\
\hline & Range & Mean \pm SD & Median & Mean & Median \\
\hline Physiological saline & $13-25$ & $19.50 \pm 4.37$ & 19 & NA & NA \\
\hline Free epirubicin & $13-26$ & $20.25 \pm 4.39$ & 21 & 3.85 & 10.53 \\
\hline Epirubicin liposomes & $15-30$ & $24.00 \pm 5.75$ & 25 & 23.08 & 31.58 \\
\hline Epirubicin plus celecoxib liposomes & $14-33$ & $26.38 \pm 6.67$ & 26 & 35.26 & 36.84 \\
\hline Targeting epirubicin plus celecoxib liposomes & $15-36$ & $28.75 \pm 7.30^{a, b}$ & 30 & 47.43 & 57.89 \\
\hline
\end{tabular}

Notes: $P<0.05$; avs physiological saline; ${ }^{b}$ vs free epirubicin; $n=8$.

Abbreviations: NA, not applicable; SD, standard deviation.
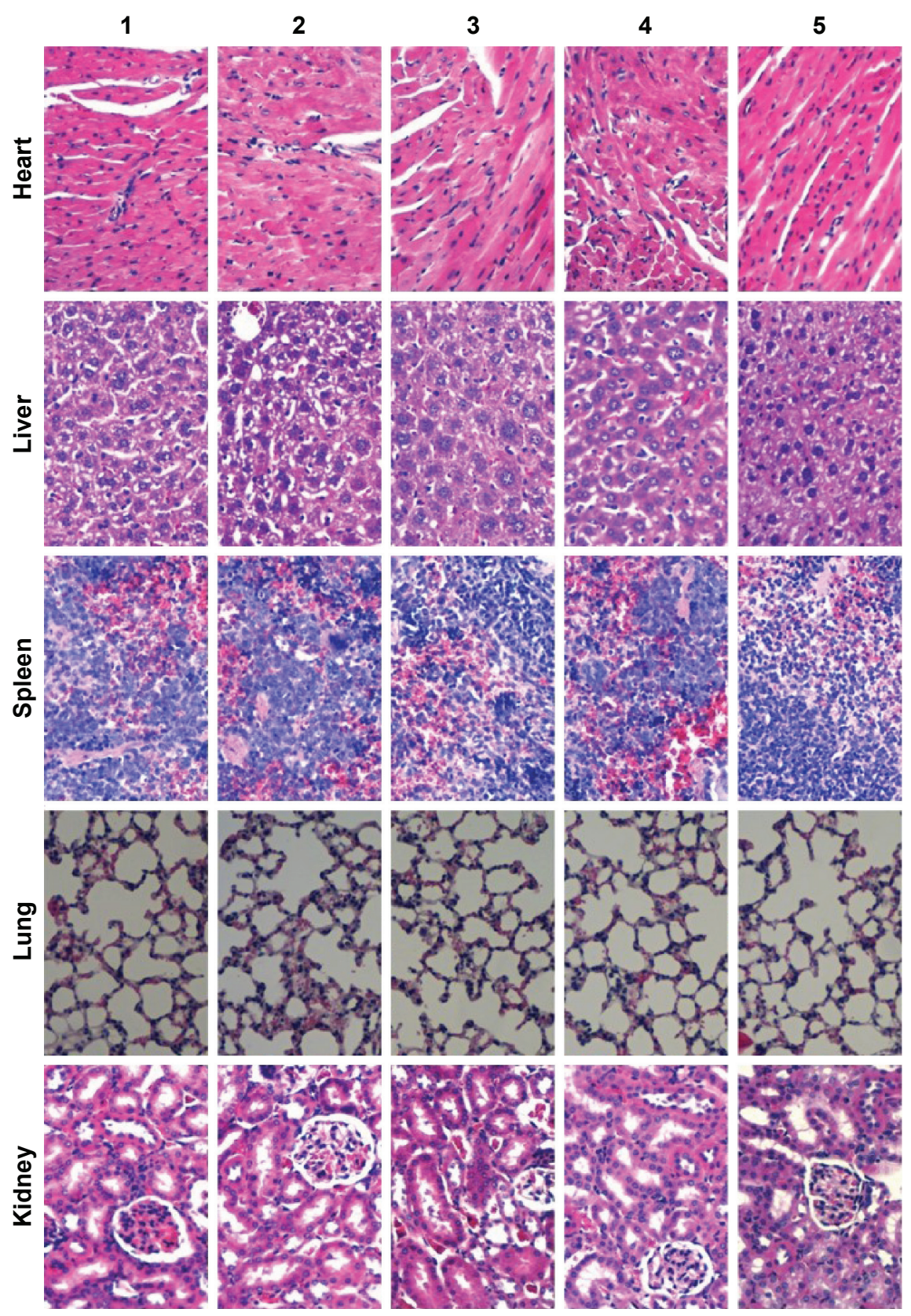

Figure 10 Preliminary toxicity evaluations in the major organs of the intracranial glioma-bearing nude mice after treatment with targeting epirubicin plus celecoxib liposomes.

Notes: I, Physiological saline; 2, free epirubicin; 3, epirubicin liposomes; 4, epirubicin plus celecoxib liposomes; 5, targeting epirubicin plus celecoxib liposomes. Paraffin sections of major organ tissues were stained with hematoxylin and eosin. Images were obtained under a microscope at 40× magnification. 
and targeting epirubicin plus celecoxib liposomes can significantly improve destructive effects on brain glioma cells in vitro. In addition to the mechanism of cellular uptake as described, the mechanism of the enhanced efficacy was also related to the induction of apoptosis.

The results of transport ability across the BBB using the coculture model indicate that the targeting epirubicin plus celecoxib liposomes could first be transported across the BBB and then exert a significant destructive effect on brain glioma cells, which were incubated in the lower compartment of the BBB (Figure 3A and B). The mechanism could also be related to electrostatic adsorption, followed by transport across the BBB mediated by clathrin-dependent endocytosis and by the heparan sulfate receptor. In addition, lipid-mediated internalization by liposomes is another possible pathway during transport across the BBB. This possibility could be evidenced by the result that the unmodified epirubicin liposomes or epirubicin plus celecoxib liposomes were able to be transported across the BBB to a certain extent and then exhibit an inhibitory effect on brain glioma cells.

The induction of apoptosis to brain glioma cells and the related mechanisms were subsequently investigated using flow cytometry and the high-content screening system, respectively. The results indicated that the targeting epirubicin plus celecoxib liposomes had significant induction of apoptosis in brain glioma cells via the apoptotic signaling pathways and the activation of apoptotic enzymes (ie, the apoptosis initiator caspase- 8 and the apoptosis effector caspase-3), upregulation of the proapoptotic protein Bax, and downregulation of the antiapoptotic protein Mcl-1 (Figure 4). This activation or inhibition initiates a cascade of apoptotic reactions, which leads to the programmed death of brain glioma cells. ${ }^{29,30}$ Both direct injury by necrosis and the induction of apoptosis contribute to the overall anticancer effect. In the present study, epirubicin was involved in induction of both direct injury and apoptosis, while celecoxib mainly played a role in the induction of apoptosis in brain glioma cells.

Tumor-cell spheroids can simulate the in vivo brain glioma environment, and exhibit solid-tumor status with multicellular gathering and the extracellular matrix. ${ }^{31}$ The fluorescence-probe coumarin-labeled targeting liposomes demonstrated strong penetrative ability into the brain glioma spheroids (Figure 5), suggesting that the PTD $_{\text {HIV-1 }}$ peptidemodified targeting liposomes would have the capability of strong penetration in the treatment of solid brain glioma.

The VM channels have been detected in clinical tumor specimens, but how to eradicate these neovasculature-like channels remains unclear. ${ }^{32}$ Unlike the neovasculatures in tumors, antiangiogenic drug therapy has demonstrated less efficiency in eliminating VM channels, which are formed by phenotype-transformed tumor cells instead of ECs and exhibit strong resistance to regular chemotherapy and to radiotherapy as well. The phenotype-transformed tumor cells are induced by the specific microenvironment and secreted induction factors, such as HIF- $1 \alpha$, under conditions of hypoxia. ${ }^{33}$ Phenotype-transformed tumor cells could bind together by themselves to form VM channels with the involvement of matrix-remolding proteins, which possibly consist of MMP-2, MMP-9, VE-Cad, FAK, PI3K, and VEGF.${ }^{34}$ In the present study, the in vitro brain glioma VMchannel models were established with brain glioma U87MG cells in a 3-D Matrigel, and a significant destructive effect to the VM channels was evident after treatment with targeting epirubicin plus celecoxib liposomes (Figure 6A). This study of the mechanism demonstrates that the downregulation of MMP-2, MMP-9, FAK, VE-Cad, and VEGF was involved in the destruction of brain glioma VM channels (Figure 7). However, PI3K, which is recognized as a signal transducer in cell growth, proliferation, and vascularization of tumors, was not significantly affected, suggesting that PI3K may not participate in the destruction of glioma VM channels after treatment with targeting epirubicin plus celecoxib liposomes.

In vivo distribution and overall anticancer efficacy were observed in the intracranial glioma-bearing nude mice. The results demonstrate that the targeting liposomes have a long circulatory effect on the circulator system, and could effectively accumulate in brain glioma sites in nude mice (Figure 8). Furthermore, targeting epirubicin plus celecoxib liposomes exhibited the strongest efficacy compared to the control formulations in the brain glioma-bearing nude mice (Figure 9A) and could effectively destroy the brain glioma VM channels simultaneously (Figure 9B). The preliminary safety evaluation indicates that there was no significant damage to the major organs after treatment with targeting epirubicin plus celecoxib liposomes (Figure 10). The destruction of VM channels and the enhanced anticancer efficacy in the brain glioma-bearing nude mice could be attributed to the following: 1) the PEGylated targeting drug-loaded liposomes allowed for prolonged circulation in the blood via escaping rapid uptake of the reticuloendothelial system;35 2) the targeting molecule PTD $_{\mathrm{HIV}-1}$ peptide promoted the transport of targeting liposomes across the BBB and mediated cellular uptake by brain glioma cells; 3 ) the incorporation of celecoxib augmented the overall anticancer efficacy by induction of apoptosis of brain glioma cells and by destruction of the 
VM channels via suppression of the VM indicators in brain glioma.

\section{Conclusion}

The targeting epirubicin plus celecoxib liposomes were able to effectively destroy brain glioma VM channels, and demonstrated significant efficacy in the treatment of intracranial glioma-bearing nude mice. The action mechanisms revealed that the nanostructured targeting epirubicin plus celecoxib liposomes were transported across the BBB, accumulated more in the brain glioma region, were targeted for uptake by brain glioma cells, and ultimately destroyed brain glioma cells by direct cytotoxic injury and the induction of apoptosis. The induction of apoptosis was related to the activation of caspase-8- and -3-signaling pathways, the activation of proapoptotic protein Bax, and the suppression of anti-apoptotic protein Mcl-1. Moreover, the destruction of brain glioma VM channels was related to the downregulation of VM channel-forming indicators, which consisted of MMP-2, MMP-9, FAK, VE-Cad, and VEGF. We conclude that targeting epirubicin plus celecoxib liposomes may be a promising formulation to treat brain glioma and destroy VM channels.

\section{Acknowledgments}

This work was supported by grants from the National Basic Research Program of China (973 program, 2013CB932501), the National Natural Science Foundation of China (81373343), and the Beijing Natural Science Foundation (7131009).

\section{Disclosure}

The authors report no conflicts of interest in this work.

\section{References}

1. Bouffet E, Tabori U, Huang A, Bartels U. Possibilities of new therapeutic strategies in brain tumors. Cancer Treat Rev. 2010;36(4):335-341.

2. Omuro A, DeAngelis LM. Glioblastoma and other malignant gliomas: a clinical review. JAMA. 2013;310(17):1842-1850.

3. Paw I, Carpenter RC, Watabe K, Debinski W, Lo HW. Mechanisms regulating glioma invasion. Cancer Lett. 2015;28;362(1):1-7.

4. Bicker J, Alves G, Fortuna A, Falcão A. Blood-brain barrier models and their relevance for a successful development of CNS drug delivery systems: a review. Eur J Pharm Biopharm. 2014;87(3):409-432.

5. Pardridge WM. Blood-brain barrier delivery. Drug Discov Today. 2007; 12(1-2):54-61.

6. Huang M, Ke Y, Sun X, et al. Mammalian target of rapamycin signaling is involved in the vasculogenic mimicry of glioma via hypoxia-inducible factor-1 $\alpha$. Oncol Rep. 2014;32(5):1973-1980.

7. Liu XM, Zhang QP, Mu YG, et al. Clinical significance of vasculogenic mimicry in human gliomas. J Neurooncol. 2011;105(2):173-179.

8. Chen YS, Chen ZP. Vasculogenic mimicry: a novel target for glioma therapy. Chin J Cancer. 2014;33(2):74-79.
9. Ju RJ, Li XT, Shi JF, et al. Liposomes, modified with PTD(HIV-1) peptide, containing epirubicin and celecoxib, to target vasculogenic mimicry channels in invasive breast cancer. Biomaterials. 2014;35(26):7610-7621.

10. Cooper I, Sasson K, Teichberg VI, Schnaider-Beeri M, Fridkin M, Shechter Y. Peptide derived from HIV-1 TAT protein destabilizes a monolayer of endothelial cells in an in vitro model of the blood-brain barrier and allows permeation of high molecular weight proteins. $J$ Biol Chem. 2012;287(53):44676-44683.

11. Rao KS, Reddy MK, Horning JL, Labhasetwar V. TAT-conjugated nanoparticles for the CNS delivery of anti-HIV drugs. Biomaterials. 2008;29(33):4429-4438.

12. Qin Y, Chen H, Yuan W, et al. Liposome formulated with TATmodified cholesterol for enhancing the brain delivery. Int J Pharm. 2011;419(1-2):85-95.

13. Liu Y, Lu W. Recent advances in brain tumor-targeted nano-drug delivery systems. Expert Opin Drug Deliv. 2012;9(6):671-686.

14. de la Fuente JM, Berry CC. Tat peptide as an efficient molecule to translocate gold nanoparticles into the cell nucleus. Bioconjug Chem. 2005;16(5):1176-1180.

15. Zhang P, Cheetham AG, Lin YA, Cui H. Self-assembled Tat nanofibers as effective drug carrier and transporter. ACS Nano. 2013;7(7): 5965-5977.

16. Taki H, Kanazawa T, Akiyama F, Takashima Y, Okada H. Intranasal delivery of camptothecin-loaded Tat-modified nanomicells for treatment of intracranial brain tumors. Pharmaceuticals (Basel). 2012;5(10): 1092-1102.

17. Simon MJ, Kang WH, Gao S, Banta S, Morrison B 3rd. Increased delivery of TAT across an endothelial monolayer following ischemic injury. Neurosci Lett. 2010;486(1):1-4.

18. Plosker GL, Faulds D. Epirubicin: a review of its pharmacodynamic and pharmacokinetic properties, and therapeutic use in cancer chemotherapy. Drugs. 1993;45(5):788-856.

19. Cowell IG, Austin CA. Mechanism of generation of therapy related leukemia in response to anti-topoisomerase II agents. Int $J$ Environ Res Public Health. 2012;9(6):2075-2091.

20. Crivellari D, Pagani O, Veronesi A, et al. High incidence of central nervous system involvement in patients with metastatic or locally advanced breast cancer treated with epirubicin and docetaxel. Ann Oncol. 2001;12(3):353-356.

21. Turini ME, DuBois RN. Cyclooxygenase-2: a therapeutic target. Annu Rev Med. 2002;53:35-57.

22. Liu X, Yue P, Zhou Z, Khuri FR, Sun SY. Death receptor regulation and celecoxib-induced apoptosis in human lung cancer cells. $J$ Natl Cancer Inst. 2004;96(23):1769-1780.

23. Vichai V, Kirtikara K. Sulforhodamine B colorimetric assay for cytotoxicity screening. Nat Protoc. 2006;1(3):1112-1116.

24. Li XY, Zhao Y, Sun MG, et al. Multifunctional liposomes loaded with paclitaxel and artemether for treatment of invasive brain glioma. Biomaterials. 2014;35(21):5591-5604.

25. Kostarelos K, Emfietzoglou D, Papakostas A, Yang WH, Ballangrud A, Sgouros G. Binding and interstitial penetration of liposomes within avascular tumor spheroids. Int J Cancer. 2004;112(4):713-721.

26. Liu T, Sun B, Zhao X, et al. HER2/neu expression correlates with vasculogenic mimicry in invasive breast carcinoma. J Cell Mol Med. 2013;17(1):116-122.

27. Chen $Y$, Jing Z, Luo C, et al. Vasculogenic mimicry-potential target for glioblastoma therapy: an in vitro and in vivo study. Med Oncol. 2012; 29(1):324-331.

28. Fu J, Wang D, Mei D, et al. Macrophage mediated biomimetic delivery system for the treatment of lung metastasis of breast cancer. J Control Release. 2015;204:11-19.

29. Friedrich K, Wieder T, Von Haefen C, et al. Overexpression of caspase-3 restores sensitivity for drug-induced apoptosis in breast cancer cell lines with acquired drug resistance. Oncogene. 2001;20(22):2449-2460.

30. Merino D, Lok SW, Visvader JE, Lindeman GJ. Targeting BCL-2 to enhance vulnerability to therapy in estrogen receptor-positive breast cancer. Oncogene. Epub 2015 Aug 10. 
31. Sciumè G, Shelton $\mathrm{S}$, Gray W, et al. A multiphase model for threedimensional tumor growth. New J Phys. 2013;15:015005.

32. Hendrix MJ, Seftor EA, Hess AR, Seftor RE. Vasculogenic mimicry and tumour-cell plasticity: lessons from melanoma. Nat Rev Cancer. 2003;3(6):411-421.

33. Tang NN, Zhu H, Zhang HJ, et al. HIF-1 $\alpha$ induces VE-cadherin expression and modulates vasculogenic mimicry in esophageal carcinoma cells. World J Gastroenterol. 2014;20(47):17894-17904.
34. Zhang S, Zhang D, Sun B. Vasculogenic mimicry: current status and future prospects. Cancer Lett. 2007;254(2):157-164.

35. Bazile D, Prud'homme C, Bassoullet MT, Marlard M, Spenlehauer G, Veillard M. Stealth Me.PEG-PLA nanoparticles avoid uptake by the mononuclear phagocytes system. J Pharm Sci. 1995;84(4):493-498.

\section{Publish your work in this journal}

The International Journal of Nanomedicine is an international, peerreviewed journal focusing on the application of nanotechnology in diagnostics, therapeutics, and drug delivery systems throughout the biomedical field. This journal is indexed on PubMed Central, MedLine, CAS, SciSearch ${ }^{\circledR}$, Current Contents ${ }^{\circledR} /$ Clinical Medicine,
Journal Citation Reports/Science Edition, EMBase, Scopus and the Elsevier Bibliographic databases. The manuscript management system is completely online and includes a very quick and fair peer-review system, which is all easy to use. Visit http://www.dovepress.com/ testimonials.php to read real quotes from published authors. 